\title{
Assessment of the pharmacy students' e-health literacy and mobile health application utilization
}

\author{
Gözde ÜSTÜN 1 (D), Sümeyra Lübeyne SÖYLEMEZ ${ }^{1}$ (D), Nazlıcan UÇAR ${ }^{1}$ (D), Mesut SANCAR ${ }^{1}$ (D), \\ Betül OKUYAN 1* (D)
}

1 Department of Clinical Pharmacy, Faculty of Pharmacy, Marmara University, Haydarpaşa 34668 İstanbul, Turkey.

* Corresponding Author. E-mail: betulokuyan@yahoo.com (B.O.); Tel. +90-216-346 4060.

Received: 16 September 2019 / Revised: 12 December 2019/ Accepted: 24 December 2019

\begin{abstract}
The aim of this study is to evaluate pharmacy students' behaviours towards mobile health applications and e-health literacy. This electronic descriptive and cross-sectional study was conducted in pharmacy students in Istanbul, Turkey for two months. A questionnaire was designed based on the previous studies to evaluate knowledge and behaviours, point of view and perception about mobile health apps in pharmacy students. Turkish version of the eHealth Literacy Scale (eHEALS) was applied to the pharmacy students. The response rate was $88.10 \%(n=229)$. Among 260 pharmacy students, mobile health apps users and male pharmacy students had statistically higher eHEALS score when compared with non-users and female pharmacy students $(p<0.05)$. Fifth-grade pharmacy students had statistically higher scores when compared with the third-grade pharmacy students $(p<0.001)$. It was found that $83.08 \%(n=216)$ pharmacy students said that mobile health apps improve patient's quality of life whereas $30.00 \%(n=78)$ thought that pharmacists have not sufficient knowledge of the using mobile health apps. As a conclusion, it was seen that pharmacy students' knowledge and behaviours towards mobile health application will be increased with improving their e-health literacy levels.
\end{abstract}

KEYWORDS: E-health literacy; knowledge and behaviours; mobile health application; pharmacy student.

\section{INTRODUCTION}

Improvements in mobile technology accelerated over the last few years with the introduction of modern smartphones and tablets. In light of these developments, interest in mobile applications (apps) has increased in clinical care [1,2]. Some applications can be used to support daily clinical practice. iTunes and Google Play stores now involve more than 20,000 medical apps [3]. Health care communication by using mobile devices has recently become widely preferred among patients and health care providers [4]. Medical mobile apps are heterogeneous in their objectives, audiences and functions. Medical smartphone apps are important source for access to drug information in pharmacy practices [5, 6]. Pharmacists can provide continuous access to quality drug information by using these apps. In the end, these mobile apps give access to health care providers to obtain clinic resources and detailed information for patient care.

Health literacy is an important factor that could effect on individual's health information search, the type of information gathered from his/her search and individual's satisfaction about the information acquired [7]. Health literacy is defined as "the degree to which individuals have the capacity to acquire, process and understand the basic health information and services required to make appropriate health decisions" [8]. E-health literacy is examined within the scope of health literacy. E-health literacy is identified as "the capacity to access, understand, evaluate and apply information acquired to solve or solve a health problem from electronic sources" [9]. Ehealth literacy is associated with various factors such as age, gender, education level, internet accessibility and income [10,11].

Health service providers should also assess the health information sources to ensure reliable health information [12]. Professionals' interest on healthcare increased with expansion in use of the Internet [13]. That is why it is important to evaluate subject's basic internet utilization and e-health literacy level. However, this evaluation would be addressed issues and inaccurate information on internet by health care providers, which would be resulted in gathering better health education to focus groups [14]. In previous studies, it is presented that undergraduate health students have low levels of e-health literacy and need to

How to cite this article: Üstün G, Söylemez SL, Uçar N, Sancar M, Okuyan B. Assessment of the pharmacy students' e-health literacy and mobile health application utilization. J Res Pharm. 2020; 24(1): 23-29. 
develop their abilities [15, 16]. In addition, it is demonstrated that university students were lack of identifying precious resources for their knowledge and often used low-level resources [14, 17].

When considering the increasing usage mobile apps in health behaviour change or disease management interventions at community pharmacy setting; it is aimed to evaluate pharmacy students' knowledge, behaviours and perceptions about mobile health app usage in pharmacy practice. That is why the relationship between pharmacy students' mobile health apps utilization and e-health literacy levels were analyse and interpret in this study.

\section{RESULTS}

Pharmacy students with grade third, fourth and fifth were selected as participants. A total of 260 (197, $75.77 \%$ female and $63,24.23 \%$ male) pharmacist students participated in this study. The response rate was $88.10 \%$. The mean age ( \pm standard deviation [SD]) of the subjects was $23.6 \pm 2.5$ years. The mean e-HEALS score was measured as $30.1 \pm 5.5$. The Cronbach's alpha was measured as 0.906 for e-HEALS and also measured 0.839 for the pharmacy students' perceptions about using mobile health apps. According to eHEALS score, male pharmacy students had statistically higher scores when compared with females $(\mathrm{p}<0.05)$ and fifth-grade pharmacy students had statistically higher scores when compared with the third grade $(\mathrm{p}<0.001)$. Demographic characteristics of students and their e-HEALS scores are shown in Table 1.

Table 1. The pharmacy students' demographic characteristics and e-HEALS score $(n=260)$.

\begin{tabular}{|c|c|c|c|}
\hline Characteristic & n (\%) & e-HEALS Score & $p$ \\
\hline \multicolumn{4}{|l|}{ Gender } \\
\hline Female & $197(75.77)$ & $29.6 \pm 0.3$ & * \\
\hline Male & $63(24.23)$ & $31.5 \pm 5.2$ & \\
\hline \multicolumn{4}{|l|}{ Pharmacy class } \\
\hline 3rd class & $59(22.69)$ & $26.3 \pm 6.3$ & $3 \mathrm{rd}-4^{\mathrm{th}} \mathrm{t}^{*}$ \\
\hline $4^{\text {th }}$ class & $46(17.69)$ & $31.4 \pm 4.5$ & $3^{\mathrm{rd}}-5^{\mathrm{th}} *$ \\
\hline $5^{\text {th }}$ class & $155(59.62)$ & $31.1 \pm 4.9$ & $4^{\text {th }}-5^{\text {th }}$ (NS) \\
\hline Age, Years & $23.6 \pm 2.5$ & $30.1 \pm 5.5$ & \\
\hline \multicolumn{4}{|c|}{ Did you use an app to monitor or change your personal health behaviour } \\
\hline Yes & $143(55.00)$ & $30.7 \pm 0.4$ & * \\
\hline No & $117(45.00)$ & $29.3 \pm 0.5$ & \\
\hline
\end{tabular}

${ }^{*} \mathrm{p}<0.05$; NS: nonsignificant

All of the students were using a smartphone or tablet device. Of them, 55.00\% ( $n=143)$ used an app to change their personal health behaviour. Among these pharmacy students, mobile health app users had statistically higher e-HEALS score when compared with non-users $(\mathrm{p}<0.05)$. Of them, $77.31 \%(\mathrm{n}=201)$ said that Internet help them to make decisions about their health conditions. The most common mobile applications that used by participants were Medscape ${ }^{\circledR}(73.85 \%, \mathrm{n}=192)$, Lexicomp ${ }^{\circledR}(29.23 \%, \mathrm{n}=76)$ and UpToDate ${ }^{\circledR}(28.08 \%, n=73)$. Most of students $(87.69 \%, n=228)$ emphasized that they want to access indications about medications using mobile health apps. The pharmacy student's knowledge and behaviours about mobile health applications are shown in Table 2.

Some of the participants $(2.69 \%, n=7)$ stated that they would not want to recommend mobile health app to the patients. Of them, $4.23 \%(\mathrm{n}=11)$ said that they were not aware of any mobile health apps. In this study, it was found that $83.08 \%(\mathrm{n}=216)$ pharmacy students said that mobile health apps improve patients quality of life whereas $30.00 \%(n=78)$ thought that pharmacists have not sufficient knowledge of the using mobile health apps. However, $43.08 \%(\mathrm{n}=112)$ students said that they need to time before applying innovations. Most of the students stated that mobile health apps improve patients' medication adherence $(81.16 \%, \mathrm{n}=211)$ and knowledge about their health condition $(81.54 \%, \mathrm{n}=212)$. Pharmacy students $(71.93 \%$, $\mathrm{n}=187$ ) also thought that mobile health apps may have positively impact on communication between patient and pharmacist. However, they were not sure about pharmacists' knowledge about of the using mobile health apps $(43.46 \%, \mathrm{n}=113)$. They also stated that necessary legal regulations must be made by professionals $(78.46 \%, n=204)$. The pharmacy students point of view about using mobile health apps is shown in Table 3 and their perceptions about using mobile health apps are shown Table 4. 
Table 2. Knowledge and behaviours about mobile health applications $(n=260)$.

\begin{tabular}{ll}
\hline Item & $\mathbf{n ~ ( \% )}$ \\
\hline Opinion about usefulness of the Internet in making decisions about their health & \\
Helpful & $201(77.31)$ \\
Not helpful & $41(15.77)$ \\
Have no opinion & $18(6.92)$ \\
The importance of accessing health resources on the Internet & $239(91.92)$ \\
Important & $14(5.39)$ \\
Not important & $7(2.69)$ \\
Have no opinion & \\
The frequency of using mobile healthcare applications in a typical week & $85(32.69)$ \\
1-5 times & $54(20.77)$ \\
$<1$ time & $23(8.85)$ \\
$>5$ times & \\
The most common mobile health apps used in the last 3 months & $192(73.85)$ \\
Medscape ${ }^{\circledR}$ & $76(29.23)$ \\
Lexicomp ${ }^{\circledR}$ & $73(28.08)$ \\
UpToDate ${ }^{\circledR}$ & \\
The most common information wanted to access via/though using mobile health & \\
applications & $228(87.69)$ \\
Indication & $209(80.38)$ \\
Contraindication/warnings & $201(77.31)$ \\
\hline Adverse reactions &
\end{tabular}

Table 3. The pharmacy students' point of view about using mobile health apps.

\begin{tabular}{lc}
\hline Item & $n(\%)$ \\
\hline \multicolumn{2}{l}{ Considering recommending a mobile health application that was created by health professionals } \\
and necessary updates is made to the patients in your professional life \\
Yes & $245(94.23)$ \\
No & $15(5.77)$ \\
The most common reason why they do not tend to recommend mobile health apps to patients \\
I am not aware of any mobile health app. & $11(4.23)$ \\
I do not trust mobile health apps. & $10(3.85)$ \\
I never thought about proposing it & $7(2.69)$ \\
I do not trust myself enough to use mobile health apps. & $5(1.92)$ \\
The most common health promotion issues they think useful in mobile healthcare application \\
Weight management & $200(76.92)$ \\
Physical activity & $184(70.77)$ \\
Smoking cessation & $176(67.69)$ \\
Receptivity to change & \\
Think for some time before adopting new ways of working & $112(43.08)$ \\
Serve as a role model for others in relation to new ways of & $70(26.92)$ \\
working & \\
Innovative with new ways of working & $69(26.54)$ \\
Cautious in relation to new ways of working; tend to change once most peers have & $8(3.08)$ \\
done so & \\
Resist new ways of working & $1(0.38)$ \\
\hline
\end{tabular}

\section{DISCUSSION}

In our study, pharmacy students' e-health literacy and mobile health application utilization were investigated. There are many factors that could impact on pharmacy students' e-health literacy levels. Bachelor's degree could be one of the factors that may affect literacy levels. Tubaishat et al. [18] carried out a study related to e-health literacy among undergraduate nursing students' and their level of e-health literacy was found moderate. On the contrary, it was seen that e-health literacy levels of the pharmacy students were 
high. However, previous studies have shown that undergraduate health students have low level of e-health literacy $[15,16,19,20]$. Robb and Shellenbarger [21] determined the gender are also as an important factor for literacy level. Similar to the present study, it was demonstrated that male pharmacy students had significantly higher score of e-health literacy than female pharmacy students [23]. In another study, it was found that female pharmacy students had higher e-HEALS scores than male pharmacy students [22]. On the contrary, Crilly et al. [23] did not find any significant differences between the gender groups in their study. These discrepancy results may be due to the relatively limited sample and differences in education level in the study sample. Dashti et al. [19] carried out a study and found that the students' grade was another factor that could affect students' e-health literacy levels. Their study indicated that pharmacy students had lower scores than students graduated from faculty of pharmacy. Similarly, it was found that when the grade level increased, the higher scores of e-HEALS were obtained in our study. These two studies are parallel and showing that health literacy increases with education level.

Table 4. The pharmacy students' perceptions about using mobile health apps.

\begin{tabular}{|c|c|c|c|}
\hline Statement & $\begin{array}{l}\text { Disagree } \\
\text { n ( } \%)\end{array}$ & $\begin{array}{c}\text { Neither } \\
\text { agree } \\
\text { nor disagree } \\
n(\%)\end{array}$ & $\begin{array}{l}\text { Agree } \\
\text { n (\%) }\end{array}$ \\
\hline $\begin{array}{l}\text { Mobile health apps seem to have the future of integrating } \\
\text { into pharmacy service delivery. }\end{array}$ & $7(2.69)$ & $55(21.16)$ & $198(76.15)$ \\
\hline $\begin{array}{l}\text { Mobile health apps should be used more when delivering } \\
\text { pharmacy services. }\end{array}$ & $10(3.85)$ & $67(25.77)$ & $183(70.38)$ \\
\hline Mobile health apps could enhance patient's quality of life. & $4(1.54)$ & $40(15.38)$ & $216(83.08)$ \\
\hline $\begin{array}{l}\text { In order to use mobile health applications in pharmacy } \\
\text { services, necessary legal regulations must be made. }\end{array}$ & $11(4.23)$ & $45(17.31)$ & $204(78.46)$ \\
\hline $\begin{array}{l}\text { Mobile health applications may change positively the } \\
\text { interaction between patient and pharmacist. }\end{array}$ & $19(7.31)$ & $54(20.77)$ & $187(71.92)$ \\
\hline $\begin{array}{l}\text { Mobile health apps may improve patients' knowledge } \\
\text { about medications and diseases. }\end{array}$ & $11(4.23)$ & $37(14.23)$ & $212(81.54)$ \\
\hline Mobile health apps could improve patients' adherence. & $5(1.92)$ & $44(16.92)$ & $211(81.16)$ \\
\hline $\begin{array}{l}\text { Pharmacists have sufficient knowledge of the using } \\
\text { mobile health applications. }\end{array}$ & $78(30.00)$ & $113(43.46)$ & $69(26.54)$ \\
\hline
\end{tabular}

Mobile healthcare apps utilization could be also affect students' e-health literacy levels. Although, the frequency of mobile health apps utilization was not high in the present study, it was found that mobile health app users had statistically higher e-HEALS score when compared with non-users. Similarly, another study indicated that adequate health literacy level was significantly associated with use of mobile health apps [24].

In our study, the majority of the students who participated in the questionnaire stated that they were using medical apps between 1-5 times a week. Similarly, the majority of students stated that they were using the medical apps at least 1 to 3 times a week in the United States [22]. These minor discrepancies may be due to differences in educational system requirements. The low frequency of medical apps utilization would be due to the lack of education of pharmacy students related to mobile health app usage and their unawareness.

In our study, $55.00 \%$ of the students were using mobile health apps to monitor or change personal health behaviour whereas $97.00 \%$ of the students were using medical apps in another study [25]. Mobile health apps safe and useful in pharmacy practice according to the study conducted in the UK [26]. Similarly, in our study, it was demonstrated that almost all of the pharmacy students agreed that the medical apps were important tools to use in pharmacy practice. Furthermore, most of the pharmacy students accepted that medical apps are significant tools for patients to use in management of their healthcare in pharmacy practice [27]. Medscape ${ }^{\circledR}$ is the most commonly used health care practice in our study. Contrary to the present study, Lexicomp ${ }^{\circledR}$ was determined as the most preferred app in a study conducted in USA [8]. This may be due to the fact that free software will be more commonly chosen in Turkey. 
The senior pharmacists stated that the technology is beneficial to combine pharmacy practice with apps. However, they also mentioned that the apps are complex and the only $2.4 \%$ of pharmacists stated that mobile health apps could be used in pharmacy practices [28]. In the present study, the applicability of mobile health apps to the pharmacy practice with the developing technology was found to be high in the questionnaire applied to the students of pharmacy. This difference can be attributed to innovative perspective of the students and the change in the system of education of students over the years.

The sample of our study was selected appropriately. The results of the study should be evaluated considering following limitations. In a part of our study, the questionnaire questions were based on the participants' opinions of view. In this case, the level of e-HEALS and the use of mobile applications led to socially acceptable responses. In addition, all the student population participating in the study are from the same university. In order to disseminate the results based on the data obtained and to minimize the variability factor, e-Health literacy and mobile application use should be investigated among students from different universities. The mobile applications usage may vary with the opportunities offered by the universities where students are registered.

\section{CONCLUSION}

In our study, it was seen that pharmacy students were willing to recommend mobile health applications to their patients if it is developed by the healthcare professionals. In addition, students think that mobile applications have high potential for delivering pharmacy practice because of improving the patients' quality of life. It has been found that mobile health apps are often used by pharmacy students to change a personal health behaviour. This suggests that these apps may be used in the delivering of health care services in the future. However, more studies should be conducted to evaluate and improve the perceptions of pharmacy students about the usage of mobile health applications in large sample size.

In our research, the usage of mobile applications on the field of health was emphasized. It was found that there was a positive relationship between the increasing the usage of mobile health applications and students' e-health literacy levels. It is also predicted that the utilization of mobile health apps in the pharmacy practice will increase the patient's adherence, knowledge and skills by pharmacy students.

In addition, it was also seen that most of the students who do not tend to recommend mobile health applications to their patients stated that they are not aware of these apps. With the integration of mobile healthcare apps into education, students' awareness of mobile healthcare apps and their recommendations may be increased. Therefore, the training programmes on mobile health apps are important and these trainings should be started at university level and address how to use mobile healthcare practices appropriately and identify mobile healthcare practices to be offered to patients. As the grade of education in pharmacy increases, the knowledge and skills of the students in health field also increase so their health literacy levels also increase. Thus, it would be better to provide mobile health applications education in the last years of the university.

\section{MATERIALS AND METHODS}

\subsection{Study sample and setting}

This electronic cross-sectional study was carried out at Marmara University Faculty of Pharmacy located in Istanbul, Turkey. The study was conducted between 20 February 2019 and 20 April 2019.

The sample size is not calculated, and the entire population is included in the study. The number of target group was 260. There are two inclusions criteria: (1) accepting to participate in the study and (2) being 18 years of age or older. A letter of invitation for study was sent as an e-mail to pharmacy students and they completed the survey online. Informed contents obtained electronically. Approval from Ethical Committee of Marmara University, Institute of Health Sciences was obtained (approval date: 18.02.2019 / approval no: 55). The required permission is also taken from the dean of the faculty.

\subsection{Data collection and evaluation}

Web-based survey was conducted through Lime-survey software. The survey instrument includes demographic characteristics ( $\mathrm{n}=4$ questions) and semi-structured questionnaire that was created based on studies in the literature to investigate knowledge and behaviours ( $\mathrm{n}=5$ questions), perception ( $\mathrm{n}=8$ questions) and point of view ( $n=4$ questions) of pharmacy students towards mobile health apps $[22,23,29,30]$. The survey that include 20 items consisted of multiple sections, which are evaluated by using five-point Likert- 
type scales. The average duration of the survey was estimated as 5-6 minutes and students were notified about the duration.

The Turkish version of the e-Health Literacy Scale (eHEALS) that consists of 8 items and score would range from 8 to 40 was also applied [23]. The higher e-HEALS score indicates higher e-health literacy level $[9,31]$.

\subsection{Data analysis}

Continuous variables were mean \pm standard deviation; ordinal and nominal data are given in $\mathrm{n}(\%)$. Chi-square test was used for the analysis of categorical variables. The analyses were performed using SPSS (Windows 11.0) programme. The normal distribution is approved by Kolmogorov-Smirnov normality test. Independent $\mathrm{T}$ test (for two groups) and ANOVA test (for more than two groups) was calculated for comparison between groups. The results were evaluated at $95 \%$ confidence interval and $p<0.05$ significance level.

Acknowledgements: The authors would like to thank the students of the faculty of pharmacy who participated in the survey.

Author contributions: Concept - G.Ü., B.O., M.S.; Design - G.Ü., S.L.S., N.U., B.O.; Supervision - G.Ü., S.L.S., N.U., B.O.; Resources - G.Ü., S.L.S., N.U., B.O.; Materials - G.Ü., S.L.S., N.U., B.O.; Data Collection and/or Processing G.Ü., S.L.S., N.U., B.O.; Analysis and/or Interpretation - G.Ü., S.L.S., N.U., B.O., M.S.; Literature Search - G.Ü., S.L.S., N.U.; Writing G.Ü., S.L.S., N.U., B.O.; Critical Reviews - G.Ü., S.L.S., N.U., B.O., M.S.

Conflict of interest statement: The authors declared no conflict of interest.

Ethics committee approval: Approval from Ethical Committee of Marmara University, Institute of Health Sciences was obtained (approval date: 18.02.2019 / approval no: 55).

\section{REFERENCES}

[1] Gillespie G. PDAs are willing, but will they be able? Health Data Manag. 2002; 10(12): 20-2, $26-8$.

[2] Payne KFB, Wharrad H, Watts K. Smartphone and medical related App use among medical students and junior doctors in the United Kingdom (UK). a regional survey. BMC Med Inform Decis Mak. 2012; 12(1): 121. [CrossRef]

[3] Frith KH, Hoy HM. Applied Clinical Informatics for Nurses: Jones \& Bartlett Learning; 2017.

[4] Shcherbakova N, Shepherd M. Community pharmacists, Internet and social media: an empirical investigation. Res Social Adm Pharm. 2014; 10(6): e75-e85. [CrossRef]

[5] Clauson KA, Marsh WA, Polen HH, Seamon MJ, Ortiz BI. Clinical decision support tools: analysis of online drug information databases. BMC Med Inform Decis Mak. 2007; 7(1): 7. [CrossRef]

[6] Polen HH, Clauson KA, Thomson W, Zapantis A, Lou JQ. Evaluation of nursing-specific drug information PDA databases used as clinical decision support tools. Int J Med Inform. 2009; 78(10): 679-687. [CrossRef]

[7] Sørensen K, Van den Broucke S, Fullam J, Doyle G, Pelikan J, Slonska Z, Brand H: Health literacy and public health: a systematic review and integration of definitions and models. BMC public health 2012; 12: 80. [CrossRef]

[8] Ratzan SC, Parker RM. In National Library of Medicine Current Bibliographies in Medicine: Health Literacy, Introduction. National Institutes of Health, US Department of Health and Human Services, USA, 2000.

[9] Norman CD, Skinner HA. eHEALS: the eHealth literacy scale. J Med Internet Res. 2006; 8(4): e27. [CrossRef]

[10] Miller EA, West DM. Where's the revolution? Digital technology and health care in the internet age. J Health Polit Policy Law. 2009; 34(2): 261-284. [CrossRef]

[11] Pálsdóttir Á. Seeking information about health and lifestyle on the Internet. Information Research 2009; $14(1): 2$.

[12] Metzger MJ, Flanagin AJ. Using Web 2.0 technologies to enhance evidence-based medical information. J Health Commun. 2011; 16(sup1): 45-58. [CrossRef]

[13] Briones R. Harnessing the web: How e-health and e-health literacy impact young adults' perceptions of online health information. Medicine 20. 2015; 4(2). [CrossRef]

[14] Stellefson M, Hanik B, Chaney JD, Tennant B. Analysis of ehealth search perspectives among female college students in the health professions using Q methodology. J Med Internet Res. 2012; 14(2): e60. [CrossRef] 
[15] Ivanitskaya L, Boyle IO, Casey AM. Health information literacy and competencies of information age students: results from the interactive online Research Readiness Self-Assessment (RRSA). J Med Internet Res. 2006; 8(2): e6. [CrossRef]

[16] Hanik B, Stellefson M. E-Health Literacy Competencies among Undergraduate Health Education Students: A Preliminary Study. Int Electron J Health Educ. 2011; 14: 46-58.

[17] Hughes M, Civilcharran S, Maharaj MS. Uncovering Web search tactics in South African higher education. S Afr J Inf Manag. 2015; 17(1): 1-8.

[18] Tubaishat A, Habiballah L. eHealth literacy among undergraduate nursing students. Nurse Educ Today. 2016; 42: 47-52. [CrossRef]

[19] Dashti S, Peyman N, Tajfard M, Esmaeeli H. E-Health literacy of medical and health sciences university students in Mashhad, Iran in 2016: a pilot study. Electron Physician. 2017; 9(3): 3966. [CrossRef]

[20] NCHEC, National Commission for Health Education Credentialing, Inc. http://www.insophe.org/Resources/Documents/NCHEC\%20Presentation.pdf, (accessed June 20, 2019).

[21] Robb M, Shellenbarger T. Influential factors and perceptions of eHealth literacy among undergraduate college students. Online J Nurs Inform. 2014; 18(3): 1.

[22] Owensby JK, Kavookjian J. Pharmacy students' perceptions of the usefulness of motivational interviewing and the use of mobile health applications on patient counseling in the future. Curr Pharm Teach Learn. 2017; 9(4): 568-575. [CrossRef]

[23] Crilly P, Hassanali W, Khanna G, Matharu K, Patel D, Patel D, et al. Community pharmacist perceptions of their role and the use of social media and mobile health applications as tools in public health. Res Social Adm Pharm. 2019; 15(1): 23-30. [CrossRef]

[24] Mackert M, Mabry-Flynn A, Champlin S, Donovan EE, Pounders K. Health literacy and health information technology adoption: The potential for a new digital divide. J Med Internet Res. 2016; 18(10): e264. [CrossRef]

[25] Donohoe KL, Matulewicz AT, Alotaibi FM, Ogbonna KC. Medical apps used during advanced pharmacy practice experiences. Curr Pharm Teach Learn. 2018; 10(2): 195-200. [CrossRef]

[26] Davies MJ, Collings M, Fletcher W, Mujtaba H. Pharmacy Apps: a new frontier on the digital landscape? Pharm Pract (Granada). 2014; 12(3): 453.

[27] Bryant JE, Richard CA. Pharmacy students' use and perceptions of Apple mobile devices incorporated into a basic health science laboratory. Curr Pharm Teach Learn. 2017; 9(1): 78-83. [CrossRef]

[28] Davies MJ, Kotadia A, Mughal H, Hannan A, Alqarni H. The attitudes of pharmacists, students and the general public on mHealth applications for medication adherence. Pharmacy practice. 2015; 13(4): 644. [CrossRef]

[29] Ming LC, Hameed MA, Lee DD, Apidi NA, Lai PSM, Hadi MA, et al. Use of medical mobile applications among hospital pharmacists in Malaysia. Ther Innov Regul Sci. 2016; 50(4): 419-426. [CrossRef]

[30] Stewart D, Cunningham S, Strath A, MacLure A, Gibson-Smith K, Rushworth GF, et al. A theoretically informed survey of the views and experiences of practicing pharmacists on research conduct, dissemination and translation. Res Social Adm Pharm. 2019; 15(11): 1298-1308. [CrossRef]

[31] Gencer ZT. Norman ve Skinner' in e-sağlik okuryazarliği ölçeğinin kültürel uyarlamasi için geçerlilik ve güvenilirlik çalişmasi. İstanbul Üniversitesi İletişim Fakültesi Dergisi. 2017(52): 131-145. 